\title{
Registration Delay and Student Performance
}

\author{
Jason Siefken 1
}

\begin{abstract}
Tracking the difference between the time a first-year student is allowed to register for a course and the time he or she does register for a course (a student's registration delay), we notice a negative correlation between registration delay and final grade in a course. The difference between a student who registers within the first two minutes they are allowed to and one who waits three weeks to register is approximately a full GPA point (on a 9 point scale). Registration delay may be a useful factor in helping to identify at-risk students, and should be taken into account as a confounding variable when doing educational studies on multi-section courses.
\end{abstract}

Keywords: college education, registration, learning analytics.

\section{Introduction}

In 2012, the Mathematics and Statistics Department made a change to the format of their introductory calculus sequence. While the section size for each lecture was increased to 250 students per lecture, the weekly tutorial sections were reduced in size to 20 students per tutorial. This meant approximately 40 tutorial sections, all scheduled on the same day, and consequently, many TAs.

After a grueling day of leading 6 tutorials, the TAs would gather to discuss how their students were doing. Most complained about the aptitude of their students, but a couple of TAs had no complaints at all. After the first midterm, some evidence started to build - the TAs that had no complaints had students that performed better. Not only that, but it appeared that there was a relationship between tutorial number and tutorial performance.

Tutorials were divided into 8 sections per lecture, and as it turned out, tutorial section 1 and 2 for each lecture section did better than all other tutorial sections and tutorial section 8 for each lecture did worse than all other tutorial sections. We hypothesized that it was not the section number that made the difference but rather that the sections, presented in numerical order in the online registration system, filled up in order, and that the correlation was actually between how quickly students registered for the course and their performance - if they took their time to register, they would be forced to select a section with a higher section number because the previous sections would be full.

This paper explores the question of whether the time a student registers for a course and his/her final mark in the course are correlated and to what extent. Our underlying assumption is:

The amount of time a student delays in registering for a course is a measure of diligence that in turn correlates with his/her final mark.

Further, we will analyze whether a section's fill-rate (how quickly a section fills to capacity) and a section's average mark relate. This last question may have implication for future education work: if a section of a course is added to be taught with an alternate teaching method, the fact that this

1 Department of Mathematics, Northwestern University, 2033 Sheridan Road, Evanston, IL 60208, siefkenj@math.northwestern.edu. 
section will be last to fill may be a confounding variable when analyzing the success of the alternate method.

\section{Related Work}

Both the personality trait of conscientiousness and various measures of procrastination have been linked to student performance. Procrastination itself has been divided into several subcategories including decisional and avoidant procrastination (Effert \& Ferrari, 1989; Milgram \& Tenne, 2000). Decisional procrastination involves putting off a task because of the stress involved in making a decision; avoidant procrastination involves delaying the start of a task because of a fear of failure. Diaz-Morales, Cohen, and Ferrari have shown that these forms of procrastination are distinct and relate to whether a person is future-goal oriented or present-goal oriented (DiazMorales, Cohen, \& Ferrari, 2008). It seems likely that both forms of procrastination might impact registration delay, but that avoidant procrastination might more severely impact academic performance.

In a meta-study combining the results of 33 individual studies, Kyung and Eun found a negative correlation between a student's level of procrastination and their performance in a course (Kim \& Seo, 2015). Vianello, Robusto, and Anselmi found that conscientiousness is positively correlated with performance (Vianello, Robusto, \& Anselmi, 2010). Though the tendency to procrastinate surely influences registration delay, the studies we reviewed did not look at the influence that procrastination has on very short time delays. In particular, it is unclear whether procrastination tendencies would cause differences in registration delays of under five minutes, and it would be interesting to investigate whether measures of procrastination affect time-delay continuously at all scales or whether different factors contribute to delays $<5$ min vs. $>20$ min vs. > 1 day.

Diligence has also been studied in relation to student performance. Galla et. al. define diligence as a willingness to stay focused on menial tasks and found that diligence positively correlates with student performance (Galla et al., 2014). In this paper, we do not use diligence in such a narrow sense, but instead use diligence colloquially to encompass dedication, motivation, and timeliness when it comes to academics.

Tangentially related is research on time-of-day effects and student performance. Hartley and Nicholls report that research on how diurnal preferences affect the performance of university students is scarce, but that "morning" and "evening" students do perform better during their preferred times (Hartley \& Nicholls, 2008). Indecision procrastination due to the lack of ideal course offerings (courses not offered in preferred timeslots or misaligned with diurnal preferences) may be a contributer to registration delay. Further research could help tease out the psychological factors that influence registration delay.

\section{Experimental Procedure}

We obtained data from the university database for the largest 20 first-year courses for the years 1998-2014. This includes 60,000 records, with possibly multiple records per student (if a student took multiple first-year courses).

For each student, there is a time when their registration window opens (when they are allowed by the online system to register) and there is a time when they actually become registered

for a course. However, if a course is full, they will be wait-listed for that course instead of being 
registered for it. Further, if a student switches sections of a course, their official registration time will be different than the time they initially registered for their original section. Because we do not think being wait-listed or switching sections are indicative of a student's diligence, we define registration time in the following way.

Definition. A student's registration time is the minimum of the time they became officially enrolled in the course, the time they were put on a wait list for the course, and the time that they first registered for some section of the same course.

A student's registration delay is the difference between their registration time and the time the online system would allow them to register.

A further complication in using registration time as a measure of a student's diligence is that some students change their mind. There are many reasons to register for a course long after you are permitted. For example, a student may change majors mid term and add courses accordingly; a student may drop a course and register for the same course next term; a student may re-register for a course upon learning his/her previous grade do not meet requirements. For these reasons, we will only analyze registration delays that are at most 19 days. This number is somewhat arbitrary, but accounts for $71 \%$ of all registrations. We have also run statistics with a cutoff of 38 days and noticed no qualitative difference in results. We will use median statistics instead of means to estimate the typical registration delay of a student who has taken multiple courses in our dataset.

\section{How Students Register}

Each student has a registration window, a timespan in which they may register for a course, which is computed from a formula involving class standing and GPA. Each student is categorized into (1) exchange student, (2) new first-year student, (3) fourth and fifth-year student, (4) graduate student, (5) third-year student, (6) first and second-year student. Registration windows are opened for category 1 first, category 2 second, and so on. Within each category, the start of a student's registration window is determined by his/her class rank. Students are informed of their registration window via email, and a registration window may open between the hours of 8:00AM and 6:00PM.
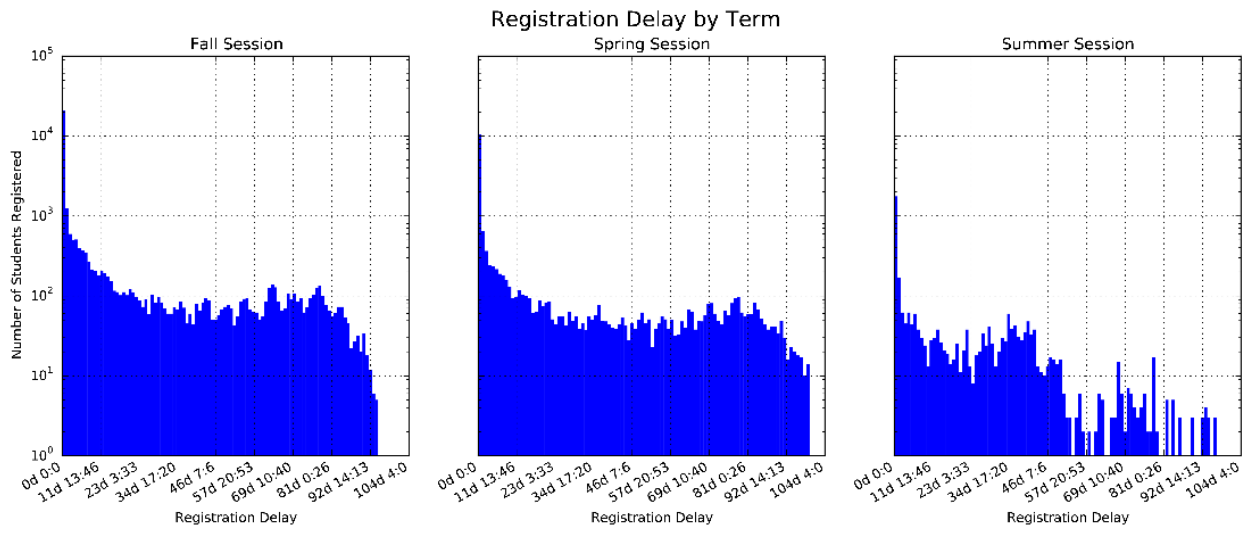

\section{Figure 1. Histogram of how students register by term for the first 100 days after their registration window opens.}


Registration patterns are similar for Fall and Spring terms, but Summer registration times are moderately different. Students may register for both their Fall and Spring courses simultaneously. Most students (52\%) register within 24 hours of the opening of their registration window. The registration time data shows that students primarily register during the day. Since the opening of a student's registration window only varies between 8:00AM and 6:00PM, we would expect to see a time-of-day effect in the aggregate registration delay data from Fall and Spring terms. This is illustrated in Figure 2.

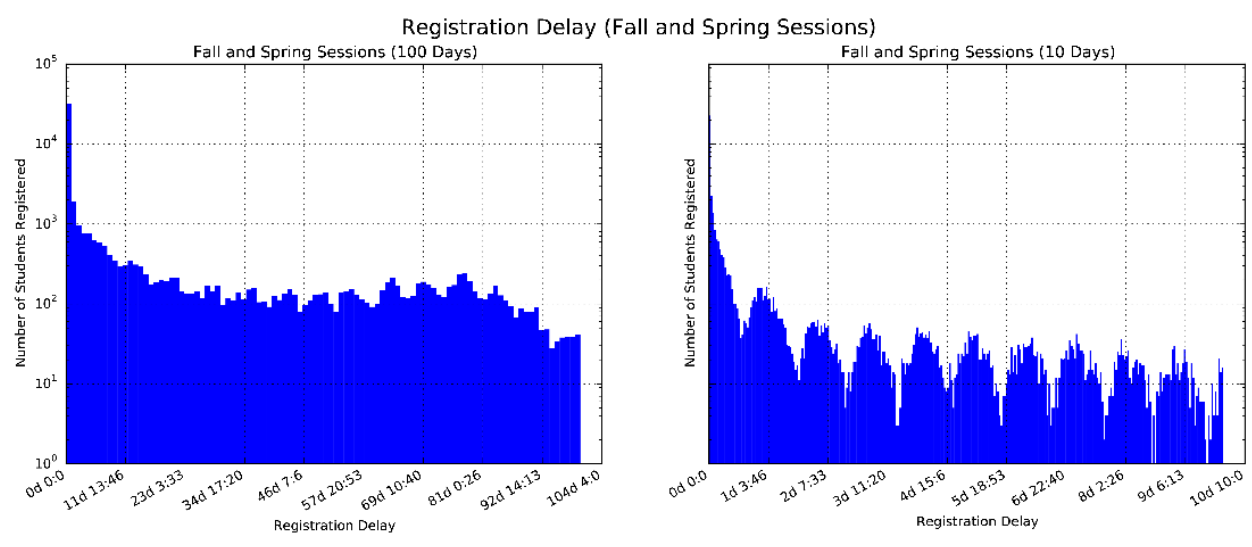

Figure 2. Aggregate histogram for Fall and Spring terms of how students register showing a clear effect of time of day.

Ignoring the time-of-day effect, the registration data for Fall and Spring appear to follow a power-law distribution with exponent -1 . Since a student may appear multiple times in the dataset, the distribution of registration delays may be influenced by an individual student's tendency to register early or late. However, looking at median registration times by student (with each student represented only once), this effect appears to be negligible, as shown in Figure 2.
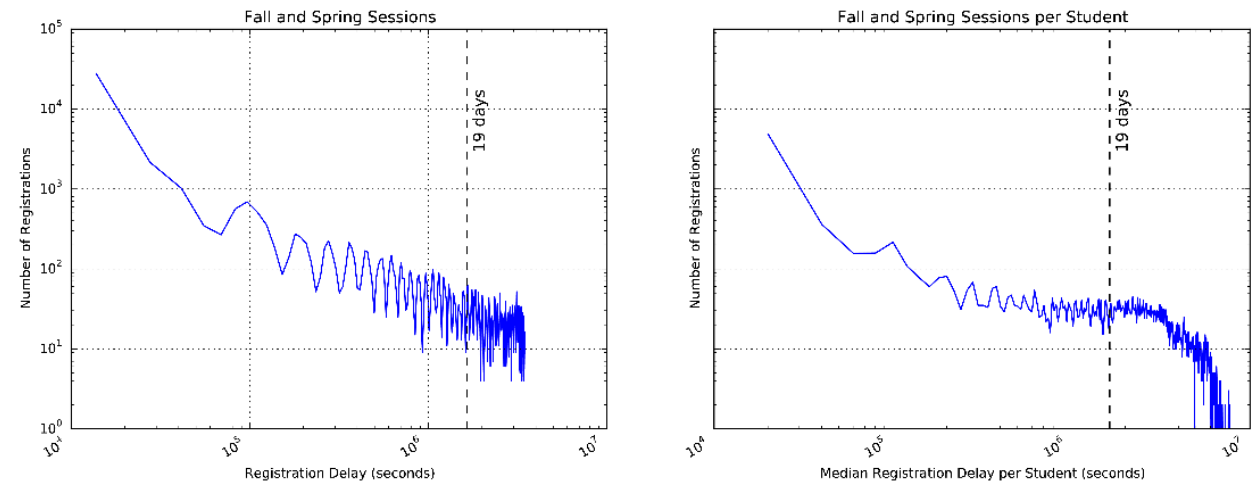

Figure 3. Log-log plot of the empirical distribution of registration delay (left) and median registration delay (right) truncated at a 40 day registration delay.

\section{Registration Delay and Grade}

Since a student may be in the dataset multiple times, we will analyze per-student statistics using a student's grade point average (GPA), computed as the mean of the final mark for every course he/she took in the dataset with letter grades converted to numbers by the following nine point scale: Journal of the Scholarship of Teaching and Learning, Vol. 17, No. 2, April 2017. 
F: 0, D: 1, C: 2, C+: 3, B-: 4, B: 5, B+: 6, A-: 7, A: 8, A+: 9.

We will restrict our analysis to Fall and Spring terms and further to registration delays less than 19 days (though lifting this restriction gives only marginally different results). Further, we will use a student's median registration delay as a representative registration delay for that student. The dataset contains 14088 records of distinct students whose median registration delay is less than 19 days.

Dividing the dataset into eight quantiles based on registration delay, we see a consistent relationship between registration delay and GPA as illustrated in Figure 4. Figure 4 shows strong skewing affects of the GPA distributions per quantile, and the GPA distribution for the first quantile (those students whose median registration time was less than two minutes) is quite skewed towards A-.

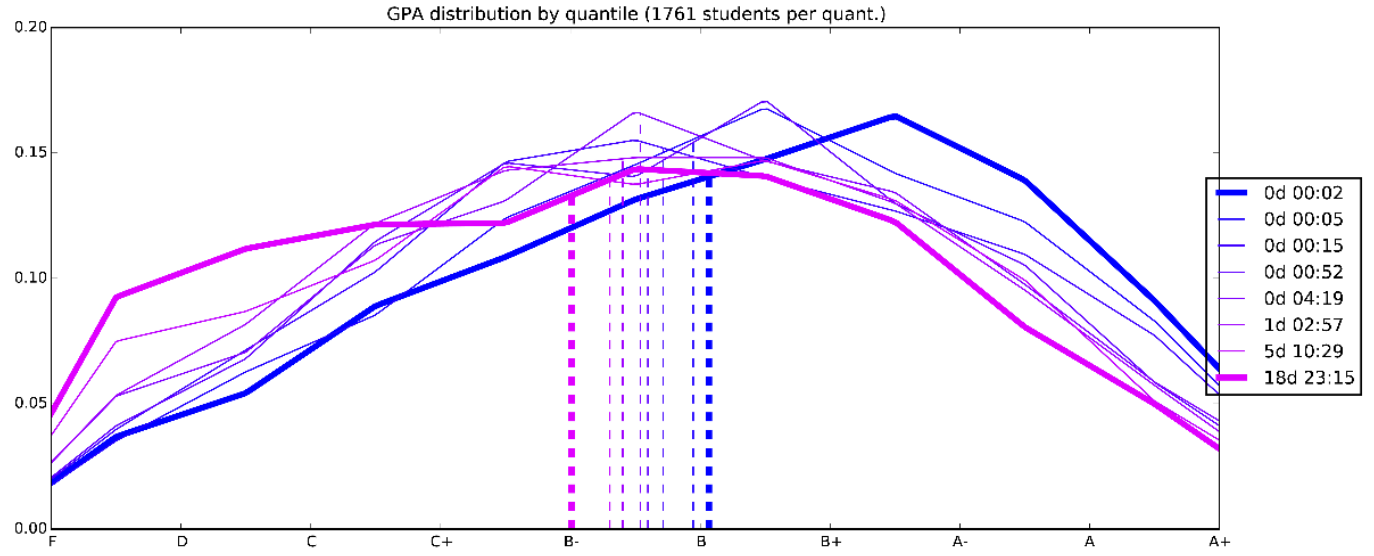

Figure 4. Distributions of 14088 records of per-student GPA divided into 8 quantiles by registration delay. Dotted lines indicate the mean GPA of each quantile. The legend indicates the maximum registration delay for each quantile. The first and the last quantile are in bold.

The relationship between mean GPA and quantile is surprisingly linear, with a least-squares line of best fit given by

$$
\text { mean GPA }=-0.968 \frac{\text { quantile }}{8}+5.06
$$

for 8 quantiles. The correlation coefficient for this regression is $r^{2}=0.97$. This means that the expected grade in a course of someone whose registration delay is less than two minutes vs. someone whose registration delay is three weeks differs by one point or $3 \%-5 \%$. This model explains approximately $2 \%$ of the variance in student grades.

Considering the data from Figure 4 in more detail, the standard deviation for the GPA distribution for each quantile ranges from 2.2 to 2.35 points. Grouping into two halves, quick registerers (those that registered within 52 minutes, 7044 students) and slow registerers (those that took longer than 52 minutes, 7044 students), we see that $59 \%$ of $\mathrm{A}+$ 's, $57 \%$ of the $\mathrm{A} / \mathrm{A}-/ \mathrm{A}+$ 's, $51 \%$ of the $\mathrm{B} / \mathrm{B}-/ \mathrm{B}+$ 's, $46 \%$ of the $\mathrm{C} / \mathrm{C}+/ \mathrm{D}$ 's, and $36 \%$ of the $\mathrm{F}$ 's are quick registerers. 
Siefken

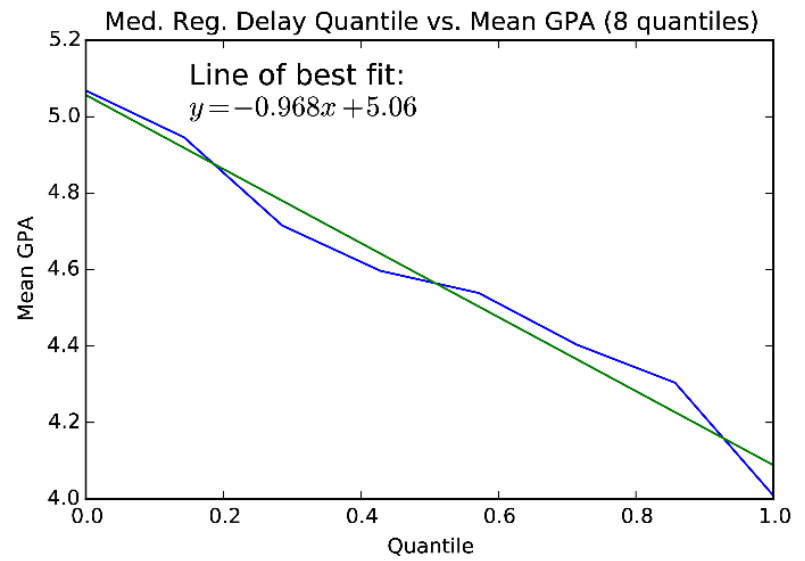

Figure 5. For 8 quantiles determined by registration delay, the mean GPA vs. the quantile. A least squares regression is also shown.

\section{How Classes Fill}

A relationship between sections of a course that fill up early and the mean grade of a course is difficult to discern from the data and may be confounded by a variety of factors. Figure $\mathbf{6}$ shows a scatter plot of the time until a section of a course is $70 \%$ full vs. the mean grade in that section. This analysis was limited to courses with at least five sections in a given term.

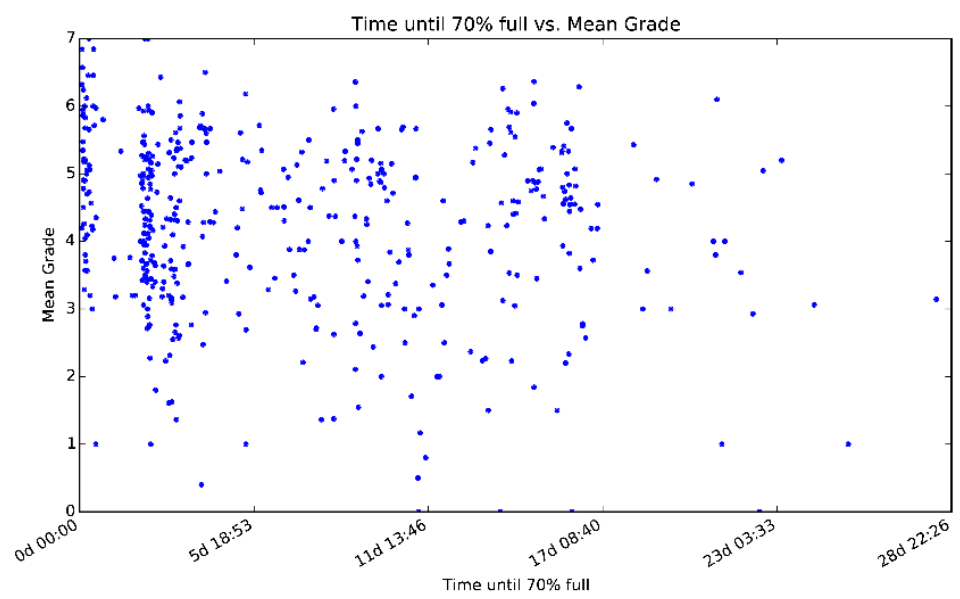

Figure 6. For courses with at least 5 sections a term, the time until a section is $70 \%$ full vs. the mean grade for that section.

The plot suggests that there is a cluster of sections that fill up quickly and a spread out cluster of sections that take longer to fill. The sections that fill up earliest have a slightly higher mean grade, but there appears to be no correlation between when the slower-to-fill sections fill and the mean grade in those sections. A course-by-course analysis of the top-scoring section of each course in a given term shows that of the 26 courses, the top-scoring section had a $75 \%$ chance of being in the top 50th percentile, and a $42 \%$ chance of being in the top 15 th percentile (compare this with the expected $50 \%$ chance of being in the 50th percentile and a $15 \%$ chance of being in the 15th percentile for uncorrelated data). The statistics for the worst-scoring section of a given 
course tells a similar story. However, besides the best and worst sections, there does not seem to be much of a relationship between when a section becomes full and the mean grade in that section.

\section{Confounding Factors}

Our analysis of when a section becomes full as an indicator of mean grade is complicated because different multi-section courses are handled in different ways. Sometimes many sections are opened at once, and as they fill, the maximum number of students allowed to register is increased. This ensures an even fill rate and a mixture of students with a low registration delays and high registration delays. At other times, as sections fill, new budgets are approved and entirely new sections are opened. These new sections are likely to be composed entirely of students with high registration delays. Our data does not distinguish between these two cases, but future research could evaluate the significance of this effect.

How a student's registration window is opened could also affect how sections fill. A student's registration window is partially determined by his or her GPA; students with higher GPAs are allowed to register earlier. The courses we have analyzed are primarily first-year courses so the effect of this should be less pronounced than in second-year courses. Correlating the absolute time of when a student's registration window opens and the student's registration delay, we notice a slight relationship showing that students whose registration window opened first tend to delay less when registering. Further research is needed to see if this effect is significant and if it becomes stronger for second and third year courses (as intuition would suggest). Additionally, whether a student's registration window is opened in the morning (8AM) or afternoon (4PM) might systematically impact registration delay, but this was not analyzed.

\section{Conclusions}

There indeed appears to be a correlation between a student's registration delay and that student's GPA, with the difference between the fastest-to-register students and the slowest-to-register students being a full GPA point on a 9 point scale.

We do not propose a causative relationship between student performance and registration delay, but instead propose that a student's registration delay is correlated to the student's diligence. Consequently, we predict that training students to register quickly will not affect how they do in a course, and in fact may render registration delay useless as a predictor of student performance and a learning-analytic tool.

Though registration delay and student performance are likely not causally linked, considering registration delay might help universities identify at-risk students. Many institutions attempt to identify at-risk students by requesting information from course instructors about their progress in class, and registration delay may be a useful factor in the formulas used to determine if a student should receive extra attention.

Further, registration delay may be a previously unaccounted for variable in many educational experiments. Though registration delay should have no impact on a statistically randomized sample of students, at our institution (and likely other universities), we run nonscientific pilot courses to evaluate new teaching methods or curricula. If an experimental section of a course is opened last and is filled primarily with delayed registerers, the effect of the experiment may be hidden by the effect of the sample bias. If homogeneity of sections is important for departmental or institutional analysis, we suggest a best practice: Ensure all sections of a course 
are opened at once with a reduced maximum number of students per section (the sections cap). As the sections fill, incrementally raise each sections cap. Doing so should ensure an even distribution of slow registerers and quick registerers across all sections. Alternatively, if one wishes to have a section distinguished among the others, a section could be opened early and then closed early to ensure only quick registerers make it in.

\section{References}

Diaz-Morales, J., Cohen, J., \& Ferrari, J. (2008). Indecision and avoidant procrastination: The role of morningness-eveningness and time perspective in chronic delay lifestyles. The Journal of general psychology, 135(3), 228-240.

Effert, R., Barbara, \& Ferrari, J. R. (1989). Decisional procrastination: Examining personality correlates. Journal of Social Behavior and Personality, 4(1), 151.

Galla, B. M., Plummer, B. D., White, R. E., Meketon, D., D’Mello, S. K., \& Duckworth, A. L. (2014). The academic diligence task (adt): assessing individual differences in effort on tedious but important schoolwork. Contemporary educational psychology, 39(4), 314-325.

Hartley, J., \& Nicholls, L. (2008). Time of day, exam performance and new technology. British Journal of Educational Technology, 39(3), 555-558.

Kim, K. R., \& Seo, E. H. (2015). The relationship between procrastination and academic performance: A meta-analysis. Personality and Individual Differences, 82, 26-33.

Milgram, N. ., \& Tenne, R. (2000). Personality correlates of decisional and task avoidant procrastination. European Journal of Personality, 14(2), 141-156.

Vianello, M., Robusto, E., \& Anselmi, P. (2010). Implicit conscientiousness predicts academic performance. Personality and Individual Differences, 48(4), 452-457. 